\title{
Deficits in urological knowledge and skills among family medicine residents in Canada
}

\author{
Elaine J. Redmond ${ }^{1,2}$; Sahar Saleem ${ }^{1}$; Trustin S. Domes ${ }^{3}$; Keith F. Rourke ${ }^{1}$ \\ ${ }^{1}$ Division of Urology, University of Alberta, Edmonton, AB, Canada; ${ }^{2}$ Tallaght University Hospital, Dublin, \\ Ireland; ${ }^{3}$ Division of Urology, University of Saskatchewan, Saskatoon, SK, Canada
}

Cite as: Can Urol Assoc J 2020 June 16; Epub ahead of print. http://dx.doi.org/10.5489/cuaj.6428

Published online June 16, 2020

$* * *$

\section{Abstract}

Introduction: The last 10-15 years has seen a decline in formal undergraduate urological education throughout Canada. Given the large volume of urological presentations in family practice, trainees need to acquire the requisite urological knowledge and skills to serve their patients. The objective of this study is to determine the perceived level of urological knowledge and skills among Canadian family medicine residents.

Methods: A 15-item anonymous online survey was distributed via email to all Canadian family medicine program directors from September to December 2018 and distributed to their residents. The survey obtained data on demographics, training, undergraduate urology experience, self-reported proficiency in interpreting urological investigations, performing common urological procedures, and managing common urologic conditions. Descriptive statistics were used to summarize data.

Results: The questionnaire was completed by 142 family medicine residents with representation from Western Canada (27.5\%), Ontario (32.4\%), and Quebec (40.1\%); 39.4\% of respondents had completed a urology rotation during medical school and only $29.1 \%$ felt that their medical training prepared them for the urological aspects of family medicine. Although the majority of respondents felt proficient in performing a digital rectal examination $(58.5 \%)$ or managing urinary tract infections $(97.9 \%)$, only a minority felt competent in performing male genitourinary examination $(40.1 \%)$, uncomplicated male $(34.5 \%)$, female $(45.8 \%)$ or difficult $(9.2 \%)$ urethral catheterization. Likewise, the minority of respondents felt comfortable managing erectile dysfunction $(41.5 \%)$, scrotal swelling (34.7\%), and scrotal pain (25.7\%).

Conclusions: There are significant deficiencies in urological knowledge and skills among family medicine residents in Canada, possibly as a consequence of insufficient educational experiences during medical training. 


\section{Introduction}

The majority of patients with urological issues will first present to their Family Physician. Although its significance is often underestimated, the initial evaluation performed by the physician frequently determines the course of investigation and ultimately treatment. Studies have previously estimated that $5-10 \%$ of consultations in primary care involve problems relating to the genitourinary tract. ${ }^{1-3}$ However, the prevalence of urological diseases in the community is expected to increase exponentially in the future due to the expanding elderly population in Canada and the often chronic nature of these conditions. Additionally, acute urological presentations such as testicular torsion, urinary retention, gross hematuria, Fournier's gangrene and renal colic require prompt recognition and specialist referral in order to optimise treatment outcomes and reduce complications. Likewise, many chronic urological complaints greatly impact patient quality of life and are treated primarily with lifestyle modifications and/or oral medications and may be well managed in the community without the need for specialist intervention. Therefore, it is important that Family Physicians have a working knowledge of the pathophysiology, examination and treatment of common urological conditions.

Concurrently and unfortunately the past decade has witnessed an insidious decline in formal urology teaching by medical schools worldwide. ${ }^{4-7}$ A recent study reported that in $65 \%$ of U.S. medical schools, it is possible for students to graduate without any exposure to clinical urology. ${ }^{8}$ Another U.S. survey revealed that only $17 \%$ of medical schools have compulsory rotations in urology compared to $99 \%$ of institutions surveyed in $1956 .{ }^{9}$ Canada has had similar trends with no medical school requiring a compulsory clinical rotation in urology. The impact of this deficit is likely significant. Previous publications have hypothesised that Family Medicine practitioners who have been exposed to clinical urology provide better urological care and make fewer inappropriate referrals. ${ }^{3,10}$ However the impact of the reduction in teaching on a Family Physician's ability to accurately assess and treat urological conditions remains unclear. The aim of this study was to investigate the selfreported competency of Family Medicine residents in managing common urological presentations. Our hypothesis is that current undergraduate medical education training does not provide Family Medicine residents with the competencies needed to effectively manage urological diseases.

\section{Methods}

Institutional ethics approval was obtained to create and distribute an anonymous online survey to family medicine residents across Canada. This survey was distributed via email to all Canadian Family Medicine Program Directors on two occasions from September to December 2018, Program directors were asked to distribute the survey to their residents. Participation in the survey was done on a voluntary basis. The survey consisted of 15 questions including participant demographics and exposure to urology during medical training (Appendix A). Respondents were invited to report their experience and proficiency in performing common urologic procedures such as male digital rectal examination (DRE), 
male and female catheterization, insertion of suprapubic catheter and vasectomy. Selfreported proficiency was assessed using a 5-point Likert scale (strongly disagree to strongly agree). Respondents were also questioned regarding their proficiency in male genitourinary (GU) examination, sexual history taking and interpretation of investigations such as CT, KUB, renal ultrasound, urinalysis and semen analysis. Finally, they were asked to describe their confidence in managing a number of common conditions such as urinary retention, hematuria, urinary tract infection, erectile dysfunction (ED), urologic malignancy and scrotal swelling. Self-reported proficiency was assessed using a 5-point Likert scale. All questionnaires were completed anonymously. Results were collated on an excel database and analysed using SPSS. Descriptive statistics were used to summarize data.

\section{Results}

One hundred and forty-two residents from Ontario $(32.4 \% ; 46 / 142)$, the Prairies (Alberta, Saskatchewan, Manitoba) $(27.5 \%$; 39/142) and Quebec $(40.1 \% ; 57 / 142)$ responded to the questionnaire. Family medicine programs from British Columbia and the Atlantic provinces were unable to or elected not to participate in the survey. The response rate of the survey was challenging to calculate as individual responses were anonymized according to ethics approval and coded only by region. Based on Canadian Resident Matching Service data there are approximately 1500 residents per year of residency. When excluding programs not or likely not participating, the total number of possible participants was likely 2000. Based on this estimate, the response rate was approximately $7 \%$. By gender, $69 \%$ of respondents were female (98/142), 28.9\% male (41/142) and 2.1\% non-binary (3/142). Eighty-six respondents $(60.6 \%)$ did not have a clinical rotation in Urology during medical school and $70.9 \%$ $(100 / 142)$ felt their exposure to urology during medical school and residency did not adequately prepare them for the urologic aspects of family medicine practice.

Hematuria, urinary tract infection, lower urinary tract symptoms (benign prostatic hyperplasia), erectile dysfunction and urinary calculi were highlighted by the residents as being the most relevant urologic components of a medical school/family medicine curriculum (Figure 1).

In spite of this, many respondents did not feel confident in managing several of these and other common urology presentations (Table 1). Most felt comfortable managing urinary tract infections $(97.2 \% ; 138 / 141)$, kidney stones $(75.6 \% ; 106 / 142)$, female urinary incontinence $(62.7 \% ; 89 / 142)$, benign prostatic hyperplasia $(62.7 \% ; 89 / 142)$ and urinary retention $(57.0 \% ; 81 / 142)$. However, self-reported proficiency in managing many common urologic presentations was low such as with hematuria $(56.5 \% ; 79 / 140)$, erectile dysfunction (41.8\%; 59/141), scrotal swelling (34.7\%; 49/141) and scrotal pain $(25.7 \%$; 39/142).

In terms of common urologic examinations and procedures, most reported low rates of proficiency in performing basic urological procedures such as digital rectal examination $(58.5 \%$; 83/142), male genitourinary examination $(40.1 \% ; 57 / 142)$, male urinary catheterization $(34.5 \% ; 49 / 142)$, female urinary catheterization $(45.8 \% ; 65 / 142)$, and difficult catheterization $(9.2 \% ; 13 / 142)$ (Figure 2). Perhaps not surprising a substantial amount of residents felt they had received insufficient training in male genitourinary examination 
$(42.3 \%$; 60/142), digital rectal examination $(23.9 \%$; 34/142) and sexual history taking $(14.1 \% ; 20 / 142)$. Self-reported experience with examination and procedures closely mirrored proficiency (Table 2). For example, 64.1\% (91/142) of respondents performed more than 10 DRE's and 42.9\% (61/142) performed more than 10 male GU examinations. Similarly, $21.8 \%(31 / 142)$ of respondents performed $>5$ male urinary catheterizations and $28.9 \%$ (41/142) of respondents performed $>5$ female catheterizations.

Although the majority of residents felt proficient in their interpretation of urinalysis and renal ultrasound, over half of respondents were concerned regarding their ability to interpret CT-KUB and the majority did not feel proficient in their ability to interpret semen analysis (Table 3).

\section{Discussion}

Urologic diseases are very common in Family Practice. The majority of urological conditions are chronic in nature and can significantly impair a patient's quality of life without necessarily affecting their lifespan. For example, approximately $17 \%$ of men and $38 \%$ of women over 60 suffer from urinary incontinence; however the overall incidence of lower urinary tract symptoms is estimated to be much higher than this. ${ }^{11,12}$ The incidence of urinary symptoms, including urinary incontinence, increases with age meaning that the prevalence of these conditions in the community is likely to increase significantly as the geriatric population in Canada increases. ${ }^{13-15}$ In a universal healthcare system such as Canada, Family Physicians play a critical role in the assessment and care of patients with urologic problems especially since the majority of patients with urological issues will first present to their Family Physician. In spite of this importance, the majority of Family Medicine residents who responded to our survey reported insufficient exposure to urology during their training. In fact, $70.9 \%$ felt their exposure to urology during training did not adequately prepare them for the urologic aspects of family practice.

This reported lack of preparedness likely directly relates to a lack of clinical exposure to urology during medical training given that the majority $(60.6 \%)$ of respondents in our survey did not have a clinical rotation in Urology during medical school. This diminished exposure to urology may result in a lack of confidence amongst many newly qualified physicians. Many urologic diseases felt to be important by Family Medicine residents had poor self-reported proficiency. For example hematuria was felt to be important by the vast majority $(81.7 \%)$ of respondents but barely over half $(56.5 \%)$ felt proficient in managing hematuria. Likewise, erectile dysfunction was felt to be important by most (53.5\%) but the minority reported being competent in this area (41.8\%). Furthermore, many respondents did not feel confident in managing several common urology presentations such as erectile dysfunction (41.5\%), scrotal swelling (34.7\%) and scrotal pain (25.7\%). It is self-evident that the absence of formal urology training during medical school and Family Medicine residency may lead to decreased confidence in managing common urologic problems and in turn have a profound effect on the treatment and management of urologic conditions in the community and may almost certainly lead to some degree of unnecessary referral. These deficiencies are even more magnified in physical examination and procedures with the minority of 
respondents comfortable with male genitourinary examination $(40.1 \%)$, male urinary catheterization (34.5\%), female urinary catheterization (45.8\%), and difficult catheterization (9.2\%). It appears that these deficiencies also closely relate to a lack of clinical exposure with only $42.9 \%$ performing over 10 male GU examinations, $21.8 \%$ performing $>5$ male urinary catheterizations and only $28.9 \%$ of respondents performing $>5$ female catheterizations.

In totality these likely represent significant deficiencies in training and may be unrewarding for the Family Physician and disadvantageous to both their patients and specialist colleagues in urology. The problem has recently become more acute given the increasing prevalence of urological conditions, the demand on secondary care services and a general drive to manage increasing numbers of patients in primary care.

According to the 2019 Canadian Residency Matching Service statistics, 33.7\% of graduating medical students in Canada enter a Family Medicine residency. ${ }^{16}$ In fact the majority of students enter fields considered to be generalist physicians who will encounter urologic patients in an undifferentiated form. Therefore it is important that the medical school curriculum also shoulders some of the responsibility in adequately preparing Family Physicians for community urological practice. The erosion in exposure to urology during medical training has been identified by a number of studies worldwide with many graduating students reporting a lack of rotations in clinical urology during medical school and limited training in digital rectal examination or male genitourinary examination. ${ }^{8,17}$ This apparent deficit in urologic education has previously been investigated by Hoag et al. ${ }^{18}$ who found that $44 \%$ of final year medical students at the University of British Columbia felt that their urological medical education was inadequate, with only $41.2 \%$ completing a urology rotation during their training. Interestingly, $100 \%$ of those who attended University of Northern British Columbia reported satisfaction with their urology exposure. The majority of students on this campus completed rotations in urology (12/13) and subsequently reported significantly higher quality teaching on digital rectal examination and male genitourinary examination compared with other campus groups where formal rotations in clinical urology were less likely. Perhaps in response to this study, Patel et a ${ }^{19}$ investigated the utility of implementing a mandatory 1 week clinical rotation in Urology and found that it was associated with increased student comfort in managing common urological conditions, including male catheterization.

Our study found that a concerning number of Family Medicine residents felt deficient in their assessment of common urological conditions. It is clear from this and other studies that the current undergraduate medical curriculum does not provide family medicine residents with the competencies needed to effectively manage urological disease. Several deficiencies have been identified by this study which may serve as an educational needs assessment that could be used to develop collaborative approaches to address these inadequacies. The Family Medicine training scheme is a two year program, therefore it is not practical to expect every resident to rotate in Urology. However, we strongly recommend that the Family Medicine curriculum be revised to incorporate shorter electives in urology, urology masterclass workshops or the opportunity to attend urology outpatient clinics in order to meet the core learning objectives outlined by the medical college of Canada (LMCC). Further development 
of a curriculum in urology focused mainly on Family Medicine residents would likely be helpful given the current time constraints limiting mandatory clinical rotations in urology.

There are several limitations to this study. A non-validated questionnaire was used and this assessed a broad but selected area of urological conditions. Furthermore, respondents self-assessed their proficiency and the results may have been influenced by a disclosure bias. The survey was emailed to all Family Medicine program directors for distribution to their residents, however on review of responses, some programs elected to not participate in the survey. Although a complete national survey performed over several consecutive years would provide a more complete description of the study question, the validity of our results is strengthened by the fact that the responses were consistent across each province. Despite these limitations we feel that this study provides a valuable insight into the current state of the urological education and self-reported competency among Family Medicine residents in Canada.

\section{Conclusions}

Our study revealed that a large number of Family Medicine residents feel their urology training needs are not being met, with a significant proportion reporting deficiencies in their management of common urological conditions. Medical school and Family Medicine curricula should be evaluated to ensure that the core learning objectives in Urology are adequately addressed and that qualified Family Medicine doctors are sufficiently prepared to manage common urological conditions in the community. 


\section{References}

1. Stubbings CA, Gowers JI. A comparison of trainee and trainer clinical experience. J R Coll Gen Pract. 1979;29(198):47-52

2. Carney TA. Clinical experience of a trainee in general practice. J R Coll Gen Pract. Jan 1979; 29(198): 40-44.

3. Teichman JM, Weiss BD, Solomon D. Urological needs assessment for primary care practice: implications for undergraduate medical education. J Urol, 1999;161: 1282

4. Benson GS. The decline of urological education in United States medical schools. J Urol 1994; 152:169

5. Redmond EJ, Kelly NP, McCarthy C, et al. Attitudes of GP trainees towards the training received in urology on the GP training scheme. Irish Journal of Medical Science (1971-). 2016 Feb 1;185(1):165-9.

6. Kan KM, Jayadevan R, Rodriguez N, et al. The current state of urological education for medical students. Urology practice. 2017 Jan;4(1):71-5.

7. Sam P, Heermans JT, Schmidt CM, et al. Current state of urologic medical school education: a scoping review. Urology. 2019 Jan 1; 123:59-63.

8. Kerfoot BP, Masser BA, Dewolf WC. The continued decline of formal urological education of medical students in the United States: does it matter? J Urol. 2006; 175(6):2243-7

9. Loughlin KR. The current status of medical student urological education in the United States. J Urol 2008;179: 1087.

10. Mishail A, Shahsavari M, Kim J, et al. Deficits in Urological Knowledge Among Medical Students and Primary Care Providers: Potential for Impact on Urological Care. J Urol. 2008; 180:2140-7.

11. Stothers L, Thom D, Calhoun E. Urologic Diseases in America Project: urinary incontinence in males-demographics and economic burden. J Urol 2005; 173:1302.

12. Thom DH, Nyguard IE and Calhoun EA: Urologic Diseases in America Project: urinary incontinence in women national trends in hospitalizations, office visits, treatment and economic impact. J Urol 2005; 173:1295.

13. Heidler S, Deveza C, Temml C, et al. The Natural History of Lower Urinary Tract Symptoms in Females: Analysis of a Health Screening Project . Eur Urol. 2007;52(6):1744-50

14. Jacobsen SJ, Girman CJ, Lieber MM. Natural history of benign prostatic hyperplasia. Urology. 2001;58(suppl 1):5-16

15. Statistics Canada Distribution of the total population by age group, observed (19212013) and projected (2014 to 2063) according to low-growth scenario, mediumgrowth and high-growth scenarios, Canada. 2014. http://www.statcan.gc.ca/pub/91520-x/2014001/c-g/desc/desc2.5-eng.htm. . Accessed September 13, 2019.

16. Canadian Resident Matching Service. http://www.carms.ca. Accessed September 13, 2019.

17. Oksana S, Tomasz S, Karolina K, et al. Assessment of knowledge concerning urology among medical students in Poland. Folia Medica Cracoviensia. 2018.

18. Hoag NA, Hamidizadeh R, MacNeily AE. Undergraduate exposure to urology: impact of the distributed model of medical education in British Columbia. Can Urol Assoc J. 2013; 7(1-2):20-5

19. Patel P, Nayak JG, McGregor TB. The value of a core clinical rotation in urology for medical students. Canadian Urological Association Journal. 2015;9(11-12):392. 


\section{Figures and Tables}

Fig. 1. Bar graph demonstrating key topics identified as being the most relevant urological components of a medical school/family medicine curriculum.

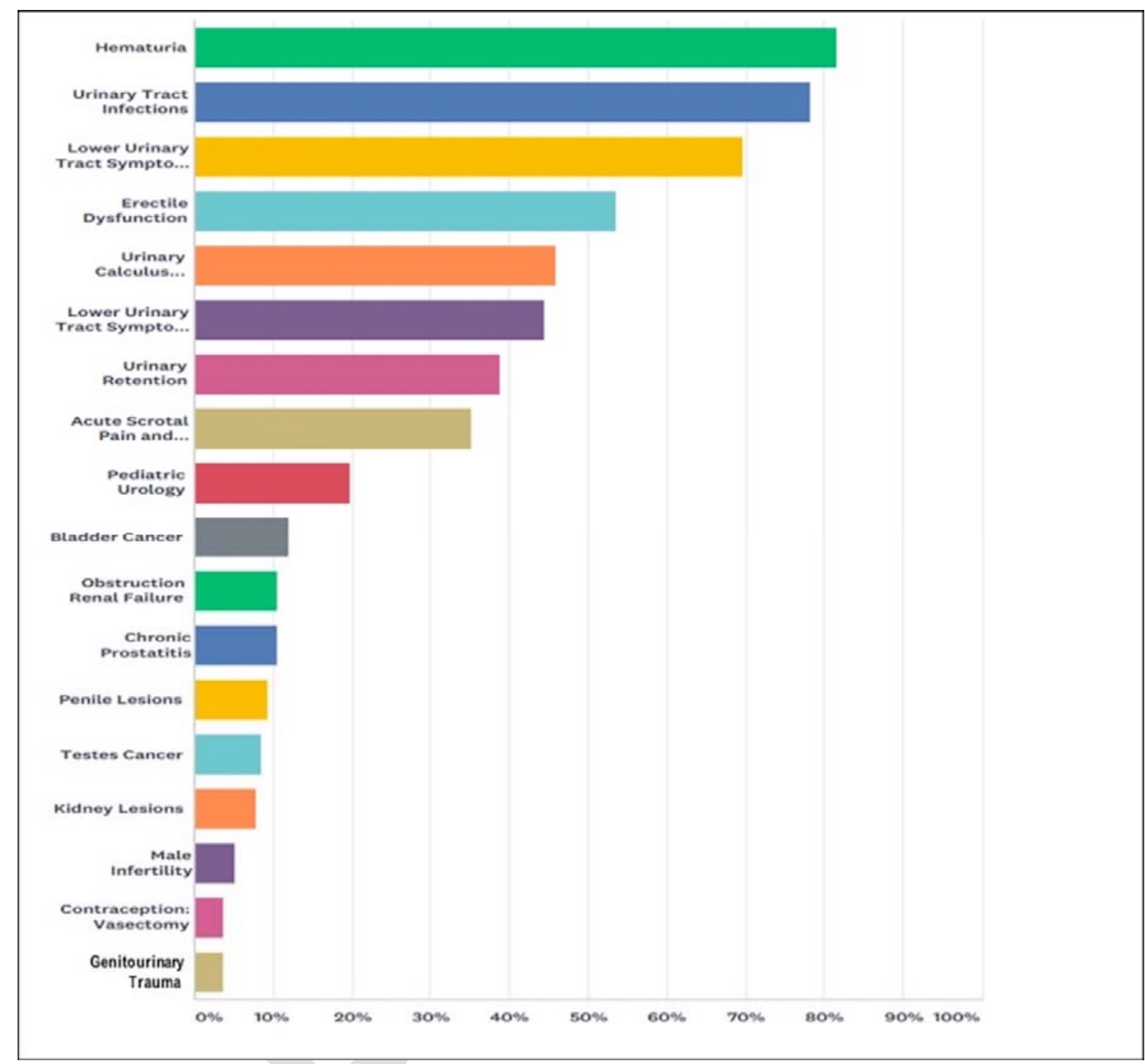


Fig. 2. Self-reported proficiency performing common genitourinary (GU) examinations and procedures including sexual history taking, digital rectal examination (DRE), male GU examination, uncomplicated male urethral catheterization, uncomplicated female catheterization, and difficult urinary catheterization.

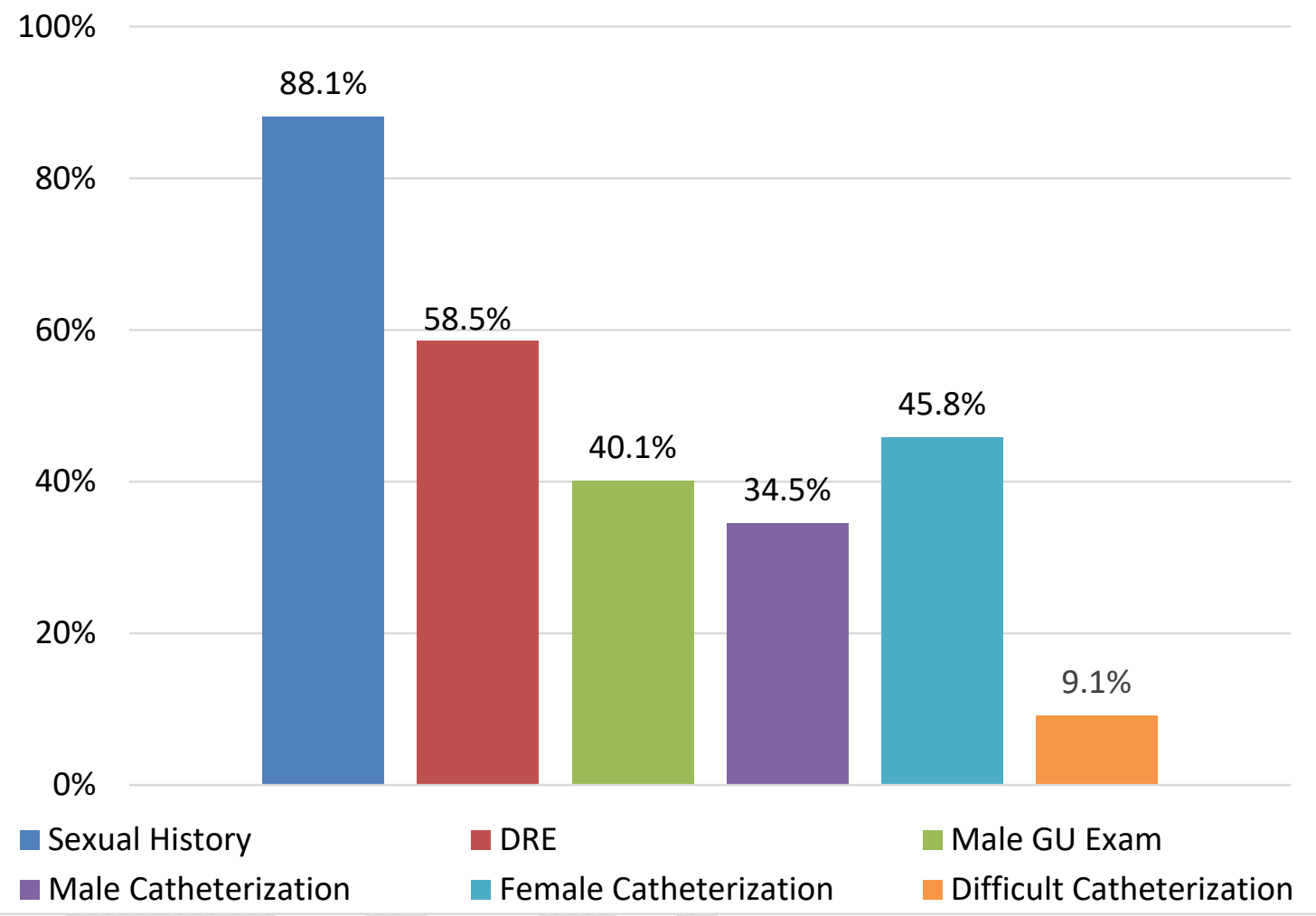




\begin{tabular}{|c|c|c|c|c|c|c|}
\hline & $\begin{array}{l}\text { Strongly } \\
\text { disagree }\end{array}$ & Disagree & Neutral & Agree & $\begin{array}{l}\text { Strongly } \\
\text { agree }\end{array}$ & $\begin{array}{c}\text { Total } \\
\text { respondents }\end{array}$ \\
\hline $\begin{array}{l}\text { Acute urinary } \\
\text { retention }\end{array}$ & $\begin{array}{l}1.4 \% \\
(2)\end{array}$ & $\begin{array}{l}19.7 \% \\
(28)\end{array}$ & $\begin{array}{c}21.8 \% \\
(31)\end{array}$ & $\begin{array}{l}52.1 \% \\
(74)\end{array}$ & $\begin{array}{l}4.9 \% \\
(7)\end{array}$ & 142 \\
\hline $\begin{array}{l}\text { Difficult urinary } \\
\text { catheterization }\end{array}$ & $\begin{array}{c}20.4 \% \\
(29)\end{array}$ & $\begin{array}{l}50.0 \% \\
(710\end{array}$ & $\begin{array}{l}20.4 \% \\
(29)\end{array}$ & $\begin{array}{l}7.8 \% \\
(11)\end{array}$ & $\begin{array}{c}1.4 \% \\
(2)\end{array}$ & 142 \\
\hline Gross hematuria & $\begin{array}{c}1.4 \% \\
(2)\end{array}$ & $\begin{array}{c}13.6 \% \\
(19)\end{array}$ & $\begin{array}{c}28.6 \% \\
(40)\end{array}$ & $\begin{array}{l}53.6 \% \\
(75)\end{array}$ & $\begin{array}{c}2.9 \% \\
(4)\end{array}$ & 140 \\
\hline $\begin{array}{l}\text { Adult urinary tract } \\
\text { infection }\end{array}$ & $\begin{array}{c}0.0 \% \\
(0)\end{array}$ & $\begin{array}{l}0.7 \% \\
(1)\end{array}$ & $\begin{array}{l}1.4 \% \\
(2)\end{array}$ & $\begin{array}{c}42.6 \% \\
(60)\end{array}$ & $\begin{array}{l}55.3 \% \\
(78)\end{array}$ & 141 \\
\hline Epididymitis & $\begin{array}{c}2.8 \% \\
(40\end{array}$ & $\begin{array}{c}21.1 \% \\
(30)\end{array}$ & $\begin{array}{c}23.9 \% \\
(34)\end{array}$ & $\begin{array}{c}45.1 \% \\
(64)\end{array}$ & $\begin{array}{l}7.0 \% \\
(10)\end{array}$ & 142 \\
\hline Prostatitis & $\begin{array}{c}2.8 \% \\
(4)\end{array}$ & $\begin{array}{c}15.5 \% \\
(22)\end{array}$ & $\begin{array}{c}31.0 \% \\
(44)\end{array}$ & $\begin{array}{c}44.4 \% \\
(63)\end{array}$ & $\begin{array}{c}6.3 \% \\
(9)\end{array}$ & 142 \\
\hline Erectile dysfunction & $\begin{array}{l}1.4 \% \\
(2)\end{array}$ & $\begin{array}{l}22.7 \% \\
(32)\end{array}$ & $\begin{array}{c}34.0 \% \\
(48)\end{array}$ & $\begin{array}{l}37.6 \% \\
(53)\end{array}$ & $\begin{array}{l}4.3 \% \\
(6)\end{array}$ & 141 \\
\hline $\begin{array}{l}\text { Urinary } \\
\text { incontinence in } \\
\text { women }\end{array}$ & $\begin{array}{l}1.4 \% \\
(2)\end{array}$ & $\begin{array}{l}9.2 \% \\
(13)\end{array}$ & $\begin{array}{c}26.8 \% \\
(38)\end{array}$ & $\begin{array}{l}52.1 \% \\
(74)\end{array}$ & $\begin{array}{l}10.6 \% \\
(15)\end{array}$ & 142 \\
\hline Kidney stones & $\begin{array}{l}0.7 \% \\
(1)\end{array}$ & $\begin{array}{c}5.6 \% \\
(8)\end{array}$ & $\begin{array}{l}19.0 \% \\
(27)\end{array}$ & $\begin{array}{c}59.9 \% \\
(85)\end{array}$ & $\begin{array}{c}14.8 \% \\
(21)\end{array}$ & 142 \\
\hline $\begin{array}{l}\text { Prostate cancer } \\
\text { screening and } \\
\text { diagnosis }\end{array}$ & $\begin{array}{l}0.7 \% \\
(1)\end{array}$ & $\begin{array}{c}9.2 \% \\
(13)\end{array}$ & $\begin{array}{l}22.7 \% \\
(32)\end{array}$ & $\begin{array}{l}58.9 \% \\
(83)\end{array}$ & $\begin{array}{l}8.5 \% \\
(12)\end{array}$ & 141 \\
\hline $\begin{array}{l}\text { Pediatric urinary } \\
\text { tract infections }\end{array}$ & $\begin{array}{l}2.1 \% \\
(3)\end{array}$ & $\begin{array}{c}16.9 \% \\
(24)\end{array}$ & $\begin{array}{c}29.6 \% \\
(42)\end{array}$ & $\begin{array}{c}45.8 \% \\
(65)\end{array}$ & $\begin{array}{c}5.6 \% \\
(8)\end{array}$ & 142 \\
\hline Scrotal pain & $\begin{array}{c}4.23 \% \\
(6)\end{array}$ & $\begin{array}{c}28.17 \% \\
(40)\end{array}$ & $\begin{array}{c}40.14 \% \\
(57)\end{array}$ & $\begin{array}{c}26.06 \% \\
(37)\end{array}$ & $\begin{array}{c}1.41 \% \\
(2)\end{array}$ & 142 \\
\hline Scrotal swelling & $\begin{array}{c}2.1 \% \\
(3)\end{array}$ & $\begin{array}{l}25.5 \% \\
(36)\end{array}$ & $\begin{array}{c}37.6 \% \\
(53)\end{array}$ & $\begin{array}{c}33.3 \% \\
(47)\end{array}$ & $\begin{array}{c}1.4 \% \\
(2)\end{array}$ & 141 \\
\hline $\begin{array}{l}\text { Lower urinary tract } \\
\text { symptoms in men }\end{array}$ & $\begin{array}{l}0.7 \% \\
(1)\end{array}$ & $\begin{array}{c}9.9 \% \\
(14)\end{array}$ & $\begin{array}{c}26.8 \% \\
(38)\end{array}$ & $\begin{array}{l}57.8 \% \\
(82)\end{array}$ & $\begin{array}{l}4.9 \% \\
(7)\end{array}$ & 142 \\
\hline
\end{tabular}




\begin{tabular}{|c|c|c|c|c|c|c|}
\hline $\begin{array}{l}\text { Number } \\
\text { performed }\end{array}$ & $\mathbf{0}$ & $1-5$ & $6-10$ & 11-20 & $>\mathbf{2 0}$ & $\begin{array}{c}\text { Total } \\
\text { respondents }\end{array}$ \\
\hline Sexual histories & $\begin{array}{l}0.0 \% \\
(0)\end{array}$ & $\begin{array}{l}9.9 \% \\
(14)\end{array}$ & $\begin{array}{c}18.3 \% \\
(26)\end{array}$ & $\begin{array}{c}16.2 \% \\
(23)\end{array}$ & $\begin{array}{l}55.6 \% \\
(79)\end{array}$ & 142 \\
\hline $\begin{array}{l}\text { Digital rectal } \\
\text { examinations }\end{array}$ & $\begin{array}{c}0.0 \% \\
(0)\end{array}$ & $\begin{array}{c}14.8 \% \\
(21)\end{array}$ & $\begin{array}{c}21.1 \% \\
(30)\end{array}$ & $\begin{array}{c}26.8 \% \\
(38)\end{array}$ & $\begin{array}{c}37.3 \% \\
(53) \\
\end{array}$ & 142 \\
\hline $\begin{array}{l}\text { Male genitourinary } \\
\text { examinations }\end{array}$ & $\begin{array}{l}0.7 \% \\
(1)\end{array}$ & $\begin{array}{c}36.6 \% \\
(52)\end{array}$ & $\begin{array}{c}19.7 \% \\
(28)\end{array}$ & $\begin{array}{c}26.1 \% \\
(37)\end{array}$ & $\begin{array}{c}16.9 \% \\
(24)\end{array}$ & 142 \\
\hline Vasectomies & $\begin{array}{l}88.7 \% \\
(126)\end{array}$ & $\begin{array}{c}9.2 \% \\
(13)\end{array}$ & $\begin{array}{c}2.1 \% \\
(3)\end{array}$ & $\begin{array}{c}0.0 \% \\
(0)\end{array}$ & $\begin{array}{c}0.0 \% \\
(0)\end{array}$ & 142 \\
\hline $\begin{array}{l}\text { Male urinary } \\
\text { catheterizations }\end{array}$ & $\begin{array}{c}16.9 \% \\
(24)\end{array}$ & $\begin{array}{c}61.3 \% \\
(87)\end{array}$ & $\begin{array}{c}21.8 \% \\
(31)\end{array}$ & $\begin{array}{c}0.0 \% \\
(0)\end{array}$ & $\begin{array}{c}0.0 \% \\
(0)\end{array}$ & 142 \\
\hline $\begin{array}{l}\text { Female urinary } \\
\text { catheterizations }\end{array}$ & $\begin{array}{c}12.0 \% \\
(17)\end{array}$ & $\begin{array}{c}59.2 \% \\
(84)\end{array}$ & $\begin{array}{l}28.9 \% \\
(41)\end{array}$ & $\begin{array}{c}0.0 \% \\
(0)\end{array}$ & $\begin{array}{c}0.0 \% \\
(0)\end{array}$ & 142 \\
\hline $\begin{array}{l}\text { Insertion of } \\
\text { suprapubic catheter }\end{array}$ & $\begin{array}{c}93.6 \% \\
(132)\end{array}$ & $\begin{array}{c}4.3 \% \\
(6)\end{array}$ & $\begin{array}{c}2.1 \% \\
(3) \\
\end{array}$ & $\begin{array}{c}0.0 \% \\
(0)\end{array}$ & $\begin{array}{c}0.0 \% \\
(0) \\
\end{array}$ & 141 \\
\hline
\end{tabular}

\begin{tabular}{|c|c|c|c|c|c|c|}
\hline & $\begin{array}{l}\text { Strongly } \\
\text { disagree }\end{array}$ & Disagree & Neutral & Agree & $\begin{array}{c}\text { Strongly } \\
\text { agree }\end{array}$ & $\begin{array}{c}\text { Total } \\
\text { respondents }\end{array}$ \\
\hline Urinalysis & $\begin{array}{c}0.7 \% \\
(1)\end{array}$ & $\begin{array}{c}2.8 \% \\
(4)\end{array}$ & $\begin{array}{c}9.9 \% \\
(14)\end{array}$ & $\begin{array}{c}65.5 \% \\
(93)\end{array}$ & $\begin{array}{c}21.1 \% \\
(30)\end{array}$ & 142 \\
\hline $\begin{array}{l}\text { Semen } \\
\text { analysis }\end{array}$ & $\begin{array}{c}26.2 \% \\
(37)\end{array}$ & $\begin{array}{c}45.4 \% \\
(64)\end{array}$ & $\begin{array}{c}19.2 \% \\
(27)\end{array}$ & $\begin{array}{l}7.1 \% \\
(10)\end{array}$ & $\begin{array}{l}2.1 \% \\
(3)\end{array}$ & 141 \\
\hline CT KUB & $\begin{array}{c}14.2 \% \\
(20)\end{array}$ & $\begin{array}{c}41.1 \% \\
(58) \\
\end{array}$ & $\begin{array}{c}25.5 \% \\
(36)\end{array}$ & $\begin{array}{l}17.7 \% \\
(25)\end{array}$ & $\begin{array}{l}1.4 \% \\
(2)\end{array}$ & 141 \\
\hline $\begin{array}{l}\text { Renal } \\
\text { ultrasound }\end{array}$ & $\begin{array}{l}9.9 \% \\
(14)\end{array}$ & $\begin{array}{c}37.3 \% \\
(53)\end{array}$ & $\begin{array}{c}26.8 \% \\
(38)\end{array}$ & $\begin{array}{c}24.7 \% \\
(35)\end{array}$ & $\begin{array}{c}1.4 \% \\
(2)\end{array}$ & 142 \\
\hline
\end{tabular}

CT KUB: computed tomography kidney ureter bladder. 
Appendix A: Web-based survey of family medicine residents

What is your gender? Male, Female, Non-Binary, Prefer Not to Say

In what region do you currently practice? British Columbia, Prairies, Ontario, Quebec, Atlantic, Canadian Territory, Other (Not Canada)

In what region did you attend medical school? British Columbia, Prairie, Ontario, Quebec, Atlantic, Canadian Territory, Other (Not Canada)

In what region did you do your residency? British Columbia, Prairie, Ontario, Quebec, Atlantic, Canadian Territory, Other (Not Canada)

In what year did you graduate from medical school?

Did you do a clinical urology rotation during medical school? Yes/No

Please describe your agreement with the following statement: "I am proficient in performing a:"

Digital Rectal Examination

Male Genitourinary Examination

Sexual History

\section{Strong Disagree}

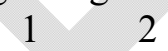

$1 \quad 2$

$1 \quad 2$
Strongly Agree

$\begin{array}{lll}3 & 4 & 5 \\ 3 & 4 & 5 \\ 3 & 4 & 5\end{array}$

Approximately how many of the following have you performed?

Digital Rectal Examination

Male Genitourinary Examination

Sexual History

$\begin{array}{llll}0 & 1-5 & 6-10 & 11-20>20 \\ 0 & 1-5 & 6-10 & 11-20>20 \\ 0 & 1-5 & 6-10 & 11-20>20\end{array}$

Please describe your agreement with the following statement. "During my medical training, I received sufficient clinical training in performing:"

Digital Rectal Examination

Male Genitourinary Examination

Sexual History

\begin{tabular}{|c|c|c|c|c|}
\hline \multicolumn{3}{|c|}{ Strong Disagree } & \multicolumn{2}{|c|}{ Strongly Agree } \\
\hline 1 & 2 & 3 & 4 & 5 \\
\hline 1 & 2 & 3 & 4 & 5 \\
\hline 1 & 2 & 3 & 4 & 5 \\
\hline
\end{tabular}

Please describe your agreement with the following statement. "I am proficient at interpreting the following investigations:"

Urinalysis

\begin{tabular}{crrrr}
\multicolumn{2}{c}{ Strong Disagree } & & \multicolumn{2}{c}{ Strongly Agree } \\
1 & 2 & 3 & 4 & 5 \\
1 & 2 & 3 & 4 & 5 \\
1 & 2 & 3 & 4 & 5 \\
1 & 2 & 3 & 4 & 5
\end{tabular}

Please describe your agreement with the following statement: "I am proficient in performing" 
Vasectomy

Urinary Catheterization (Male)

Urinary Catheterization (Female)

Insertion of Suprapubic Catheter

\begin{tabular}{ccccc}
\multicolumn{2}{c}{ Strong Disagree } & & \multicolumn{2}{c}{ Strongly Agree } \\
1 & 2 & 3 & 4 & 5 \\
1 & 2 & 3 & 4 & 5 \\
1 & 2 & 3 & 4 & 5 \\
1 & 2 & 3 & 4 & 5
\end{tabular}

How many of the following procedures have you performed?
Vasectomy
Urinary Catheterization (Male)
Urinary Catheterization (Female)
$0 \quad 1-5 \quad 6-10 \quad 11-20>20$
$0 \quad 1-5 \quad 6-10 \quad 11-20>20$
$0 \quad 1-5 \quad 6-10 \quad 11-20>20$

Please describe your agreement with the following statement: "I am proficient in managing the following clinical scenarios"

Acute Urinary Retention

Difficult Urinary Catheterization

Hematuria

Adult Urinary Tract Infection

Lower urinary tract symptoms in men

Epididymitis

Prostatitis

Erectile Dysfunction

Urinary Incontinence

Kidney Stones

Prostate Cancer Diagnosis

Pediatric Urinary Tract Infection

Acute Scrotal pain

Scrotal Swelling

\begin{tabular}{ccccc}
\multicolumn{2}{c}{ Strong Disagree } & & \multicolumn{2}{c}{ Strongly Agree } \\
1 & 2 & 3 & 4 & 5 \\
1 & 2 & 3 & 4 & 5 \\
1 & 2 & 3 & 4 & 5 \\
1 & 2 & 3 & 4 & 5 \\
1 & 2 & 3 & 4 & 5 \\
1 & 2 & 3 & 4 & 5 \\
1 & 2 & 3 & 4 & 5 \\
1 & 2 & 3 & 4 & 5 \\
1 & 2 & 3 & 4 & 5 \\
1 & 2 & 3 & 4 & 5 \\
1 & 2 & 3 & 4 & 5 \\
1 & 2 & 3 & 4 & 5 \\
1 & 2 & 3 & 4 & 5 \\
1 & 2 & 3 & 4 & 5
\end{tabular}

Do you feel your exposure to urology during medical school and residency adequately prepared you for urologic aspects of family medicine practice? Yes/No

What FIVE areas in urology do you feel are most important to teach in a medical school and family medicine curriculum?
a. Urinary calculus disease
b. Hematuria
c. Urinary tract infections
d. Lower urinary tract symptoms (benign prostatic hyperplasia)
e. Lower urinary tract symptoms (overactive bladder)
f. Urinary incontinence
g. Prostate cancer: PSA screening and diagnosis
h. Prostate cancer: treatment
i. Erectile dysfunction 
j. Acute scrotal pain and swelling

k. Pediatric urology

1. Urinary Retention

m. Penile lesions

n. Kidney lesions

o. Bladder cancer

p. Male infertility

q. Contraception: Vasectomy

r. Obstructive renal failure

s. Testes cancer

t. Chronic prostatitis: chronic pelvic pain syndrome

u. Genitourinary trauma

Any there any topics not listed that you feel are important in an undergraduate urology curriculum? 